\title{
Analisis Kreativitas Cindercella dalam Melakukan Make Up Art
}

\author{
Monica, Gregorius Genep Sukendro \\ monicaahandraa@gmail.com, geneps@fikom.untar.ac.id
}

Fakultas Ilmu Komunikasi Universitas Tarumanagara

\begin{abstract}
Make up is one part of people's lives at this time. As the development of the make up era has many variations, one of them is Make Up Art. This study aims to discuss Cindercella's creativity in communicating make up art. Cindercella is a beauty vlogger who is quite wellknown and that her make up art is inherent in many people. The author is interested in analyzing the creativity of make up art made by Cindercella because the make-up that is made is very unique, interesting, and creative. The purpose of this study was to find out the reasons for communicating and doing make-up art by Cindercella. In this study using several theories including the theory of communication, self-identity, and creativity. The type of methodology of this research is qualitative with descriptive case study method. This data collection technique uses the method of in-depth interviews, observations and other matters related to this study to find out the creativity carried out by Cindercella in communicating make-up art. It can be concluded, the make up art by Cindercella is unique and creative so that it makes itself known by many people and makes the make up art an identity that has been attached to him. The purpose of make-up art is done by Cindercella so she can become a trensetter.
\end{abstract}

Keywords: Cindercella, make up, creativity, personal identity.

\begin{abstract}
Abstrak
Make Up merupakan salah satu bagian dari kehidupan masyarakat pada saat ini. Seiring perkembangan jaman make up mempunyai banyak variasi, salah satunya Make Up Art. Penelitian ini bertujuan untuk membahas mengenai kreativitas Cindercella dalam mengkomunikasikan make up art. Cindercella adalah seorang beauty vlogger yang sudah cukup ternama dan make up art sudah melekat pada dirinya yang dikenal banyak orang. Penulis tertarik untuk menganalisa kreativitas make up art yang dibuat oleh Cindercella karena make up yang dibuat sangat unik, menarik, dan kreatif. Tujuan dari penelitian ini adalah untuk mengetahui alasan mengkomunikasikan dan melakukan make up art yang dilakukan oleh Cindercella. Dalam penelitian ini menggunakan beberapa teori antara lain teori komunikasi, identitas diri, dan kreativitas. Jenis metodelogi penelitian ini adalah kualitatif dengan metode studi kasus deskriptif. Teknik pengumpulan data ini dengan menggunakan metode wawancara mendalam, observasi dan hal-hal lain yang terkait dengan penelitian ini untuk mengetahui kreativitas yang dilakukan oleh Cindercella dalam mengkomunikasikan make up art. Dapat disimpulkan, make up art yang dilakukan oleh cindercella berbeda unik dan kreatif sehingga membuat dirinya dikenal oleh banyak orang dan menjadikan make up art tersebut sebagai identitas yang sudah melekat pada dirinya. Tujuan make up art yang dilakukan oleh cindercella agar dirinya dapat menjadi trensetter.
\end{abstract}

Kata kunci: Cindercella, Make Up, Kreativitas, identitas diri. 


\section{Pendahuluan}

Pada era perkembangan jaman sekarang ini, banyak sekali hal yang berkembang. Salah satunya dari dunia kecantikan di Indonesia yang juga menjadi marak bagi masyarakatnya. Make up pada dasarnya sudah ada dan sudah dikenal dari jaman mesir kuno sampai saat ini. Seiring perkembangan jaman, make up juga tentunya mengikuti trend dan mempunyai perubahan-perubahan yang semakin terlihat lebih modis pada zamannya. Bagi para kaum hawa Make Up dapat dibilang sebagai suatu hal yang sudah menjadi satu bagian dari keseharian. (http://parasayu.net/perkembangan-dunia-makeup-dari-masa-ke-masa-hinggasampai-saat-ini/)

Sampai saat ini make up juga mempunyai beberapa variasi, yaitu make up korektif, make up seni, dan juga make up art (karakter).Make up art biasanya digunakan untuk memunculkan suatu karakter di televisi dan film, pada saat ingin merubah karakter seseorang agar sesuai dengan tokoh yang diperankannya. Seperti yang dilakukan oleh salah satu beauty vlogger ternama di Indonesia yaitu marcella febrianne atau yang dikenal dengan cindercella ini lebih memilih untuk melakukan make up art dibandingkan dengan beauty make up.

Cindercella mengawali karirnya sebagai seorang Beauty Vlogger pada akhir tahun 2015, dan namanya cukup terkenal dikalangan beauty vlogger indonesia. Ia juga pernah meraih gelar Beauty Influencer Of The year dari salah satu ajang penghargaan bergengsi, dan pernah diundang menjadi salah satu juri tamu pada acara Asia's Next Top Model pada tahun 2017. Sampai saat ini juga ia telah berkolaborasi dengan beberapa brand Make Up ternama salah satunya yaitu Make Over.

Selain itu jika dilihat cindercella lebih banyak melakukan make up art ketimbang beauty make up, dimana make up art yang ia gunakan selalu colourfull. Cindercella membuat make up art yang menyerupai beberapa tokoh-tokoh ternama diantaranya yaitu galactic deer, floral demon,zombie, dan beberapa macam make up art lainnya. Tidak semua beauty vlogger dapat melakukan make up art dan tidak semua berani untuk mengkomunikasikan make up art tersebut.

Pada dasarnya, setiap orang menggunakan make up untuk dapat mempercantik diri dan juga penampilannya agar terlihat lebih menarik. Dalam melakukan make up art juga sangat diperlukan sebuah kreativitas, agar dapat lebih mudah untuk menuangkan semua ide yang dimiliki dan membuat suatu hasil karya seni ataupun make up yang unik, karena kreativitas juga sangat diperlukan dalam proses pembuatan make up karakter dengan begitu cindercella sebagai seorang beauty vlogger juga dapat lebih mudah untuk membuat hasil karya make up art yang unik, berbeda, dan kreative.

Dunia kreativitas di Indonesia sekarang ini semakin berkembang, salah satunya dengan adanya seorang beauty vlogger pada konten platform media social. Menurut Utami Munandar (2009:12) Kreativitas adalah suatu hasil interaksi antara individu dan lingkungannya, serta kemampuan untuk membuat kombinasi baru, berdasarkan data, informasi, ataupun unsur-unsur yang sudah ada atau dikenal sebelumnya, yaitu dengan semua pengetahuan dan pengalaman seseorang yang telah ia peroleh melalui lingkungan sekitarnya dan dapat ia kombinasikan menjadi suatu hal yang baru.

Tidak semua manusia memiliki kreativitas dan juga tidak semua manusia yang memiliki kreativitas memiliki keberanian untuk menuangkan kreativitasnya dalam bentuk seni ataupun sebuah make up. Selain itu juga, Cindercella berani melakukan 
dan mengkomunikasikan make up art tersebut melalui beberapa platform media social salah satunya platform yang ia gunakan adalah Youtube. Sehingga dapat memudahkan masyarakat untuk mengakses informasi atau tutorial terkini tentang make up art dengan mudah yang dibuat oleh cindercella. Penulis menjadi tertarik untuk menganalisa dan mengenal lebih dalam seorang Cindercella, dikarenakan keberanian dalam melakukan dan mengkomunikasikan serta kreativitas make up art yang ia buat.

Berdasarkan dari latar belakang tersebut, maka rumusan masalah yang ada yaitu:

a. Mengapa Cindercella Mengkomunikasikan Make Up Art?

Dan adanya tujuan dari penelitian yang ada yaitu:

a. Mengetahui alasan cindercella dalam mengkomunikasikan make up art

Hasil dari penelitian ini menunjukkan bahwa cindercella mengkomunikasikan make up art bahwa make up yang dilakukannya berbeda, unik, dan kreative dan juga dapat memberikan kesan cantik. Cindercella juga ingin menjadi seseorang yang menonjol atau menjadi trensetter yang terlihat berbeda dengan yang lainnya. Hal tersebut ia lakukan sehingga make up art tersebut dapat melekat pada dirinya dan menjadikannya sebagai identitas diri.

\section{Metode Penelitian}

Dalam penelitian ini, jenis penelitian yang penulis gunakan adalah pendekatan penelitian kualitatif. Penelitian ini dilakukan oleh penulis untuk mengetahui kreativitas make up art yang dibuat oleh cindercella. Menurut Bodgan dan Taylor (dalam Moleong, 2012:4) menyatakan bahwa penelitian kualitatif adalah sebagai prosedur penelitian yang menghasilkan data deskriptif yang berupa kata-kata baik tertulis maupun lisan dari orang-orang dan perilaku yang dapat diamati.

Metode strategi penelitian yang digunakan oleh peneliti dalam penelitian skripsi ini adalah dengan menggunakan metode deskriptif pendekatan studi kasus. Menurut Nazir (2011) Metode penelitian deskriptif adalah suatu metode dalam meniliti status kelompok manusia atau individu, suatu objek, suatu kondisi, suatu sistem pemikiran, ataupun suatu kelas peristiwa pada masa sekarang. Menurut Maxfield (dalam Nazir, 2011:57) Studi kasus adalah metode penelitian yang bertujuan untuk meneliti tentang suatu subjek penelitian atau individu yang berkenan dengan suatu fase spesifik atau khas dari keseluruhan personalitas. Peneliti menggunakan studi kasus sebagai metode penelitian dikarenakan peneliti ingin mencari dan mengetahui serta mengumpulkan informasi-informasi secara lebih mendalam.

Dalam penelitian ini, peneliti menggunakan beberapa metode teknik pengumpulan untuk dapat memperoleh data dan juga informasi lebih dalam dengan berbagai cara seperti; wawancara, observasi, studi kepustakaan, dan penelusuran data online. Subjek dalam penelitian ini adalah Cindercella dan objek dalam penelitian ini adalah cara cindercella mengkomunikasikan make up art.

Teknik analisis data yang digunakan untuk penelitian ini adalah teknik analasis data kualitiatif menurut Miler dan Huberman. Menurt Miler dan Huberman (1992) dalam Gunawan (2014:210-211) Teknik analisis data kualitatif ini terdiri juga dari tiga teknik analisis yaitu; reduksi data, penyajian data, dan kesimpulan atau verifikasi. 
Sedangkan salah satu teknik keabsahan data yang digunakan dalam hasil penelitian ini adalah dengan melakukan triangulasi. Triangulasi adalah teknik pemeriksaan data yang memanfaatkan sesuatu yang lain di luar data yang sudah ada itu untuk keperluan pengecekan kembali atau sebagai pembanding terhadap data yang sudah ada (Moleong, 2012:330). Menurut Denzin dalam (Imam Gunawan 2014: 219). salah satu cara paling penting dalam langkah pengujian keabsahan hasil penelitian data adalah dengan melakukan triangulasi sumber, dan metode.

Dalam penelitian ini penulis menggunakan 2 langkah uji keabsahan data, yaitu dengan triangulasi dengan sumber dan triangulasi dengan metode.

\section{Hasil Temuan dan Diskusi}

Temuan penelitian yang dilakukan oleh peneliti dalam hal ini merupakan cindercella adalah seorang beauty vlogger di Indonesia yang sudah cukup terkenal dikalangannya, ia menekuni dunia make up sejak umurnya 16 tahun, dan ia memulai karir nya sebagai seorang beauty vlogger pada akhir tahun 2015 dan semenjak itu namanya mulai membesar sehingga banyak dikenali banyak orang karena kreativitas make up yang ia lakukan tersebut berbeda dan unik sehingga menarik perhatian banyak orang. Dalam penelitian ini, penulis mempunyai satu key informan dan dua narasumber ahli. Pada penelitian ini penulis akan melakukan teknik pengumpulan data dengan melakukan wawancara mendalam untuk dapat memperoleh data kualitatif yang diperlukan yang sesuai dengan penelitian yang akan diteliti.

Cindercella menjadi seorang beauty vlogger juga harus mempunyai keunikan yang berbeda dan kreativitas yang tinggi, agar dapat menonjolkan identitas diri yang ia miliki dan berbeda dengan beauty vlogger lainnya.

Penulis menemukan beberapa cara cindercella mengkomunikasikan make up art yaitu dengan komunikasi, identitas diri, kreativitas yang akan penulis jabarkan sebagai berikut:

\section{Komunikasi}

Komunikasi tentunya sangat dibutuhkan pada setiap manusia. Komunikasi ini juga menjadi salah satu cara untuk mengkomunikasikan make up karakter yang di buat oleh Cindercella untuk menunjukkan konten make up karakter yang dibuatnya.

Menurut West dan Turner, Effendy (2006) bahwa komunikasi sebagai proses penyampaian pikiran atau perasaan oleh seseorang kepada orang lain dengan menggunakan lambang-lambang yang bermakna sebagai sebuah proses kegiatan menyampaikan pesan kepada orang lain menggunakan simbol-simbol yang dapat dipahami oleh kedua belah pihak sehingga pesan yang disampaikan dapat diterima dengan baik oleh pihak-pihak yang berkomunikasi.

Cindercella selalu mengkomunikasikan make up yang ia lakukan atau hal-hal lainnya ke dalam media sosialnya tersebut, walaupun mungkin hasilnya tidak sesuai dengan yang diinginkan namun cindercella tetap melakukan apapun dan ia komunikasikan kepada viewers nya. Dengan begitu penulis menyimpulkan bahwa komunikasi yang ia lakukan dengan mengunggah video atau hal lainnya disukai oleh masyarakat dan juga dapat diterima serta dipahami oleh viewers nya dengan baik.

2. Identitas Diri

Identitas diri didasarkan pada keunikan karakteristik yang dimiliki oleh pribadi seseorang. Dengan hobby dan bakat serta kreativitas yang dimiliki oleh 
Cindercella dapat menjadikannya sebagai identitas dirinya yang cukup dikenal oleh banyak orang.

Menurut Chris Barker (2004:172), konstruksi identitas diri adalah bangunan identitas diri, memperlihatkan siapa diri kita sebenernya dan kesamaan kita dengan sejumlah orang dan apa yang membedakan kita dengan yang lain. Dilihat dari bentuknya, terdapat bentuk identitas yakni, identitas sosial dan identitas diri. Berikut pengertiannya:

- Identitas Sosial

Identitas sosial terbentuk dari keanggotaan seseorang dalam suatu kelompok kebudayaan. Tipe kelompok antara lain, umur, gender, kerja, agama, tempat, dan kelas sosial.

- Identitas Diri

Identitas diri didasarkan pada keunikan karakterisitik pribadi seseorang. Seperti karakter, bakat, kemampuan, dan lain sebagainya.

Cindercella termasuk dalam identitas diri karena hal tersebut juga dapat dilihat bahwa identitas diri merupakan sebuah bakat atau kemampuan yang dimiliki oleh cindercella yang dimana ia melakukan dalam sebuah make up, dimana tidak semua orang berani menggunakan make up art tersebut dan bisa membuat make up art.

Bakat dan kemampuan yang ia miliki menjadikan make up karakter tersebut sebagai suatu identitas diri nya yang dikenali oleh orang banyak. Berani memperlihatkan bagaimana sosok seorang cindercella dengan keunikan make up nya yang colourfull serta kreativitas yang dimiliki itu merupakan salah satu hal yang membedakan dirinya dengan yang lainnya.

\section{Kreativitas}

Dalam dunia kecantikan juga banyak sekali persaingan-persaingan, begitu pun juga dengan Beauty Vlogger ataupun Beauty Influencer yang semakin marak di platform media sosial. Dengan begitu Beauty Vlogger juga harus menunjukkan dan mempunyai kreatifivitas untuk menunjukkan kelebihan yang dimilikinya dan bersaing dengan yang lainnya.

Menurut Supriyadi dalam Yeni Rachmawati dan Euis Kurniati (2005:15) mengutarakan bahwa kreativitas adalah suatu kemampuan seseorang untuk melahirkan sesuatu yang baru, baik berupa gagasan maupun karya nyata yang relatif berbeda dengan apa yang telah ada.

Walaupun cindercella seringkali terinspirasi dari orang lain, namun ia dapat membuat make up tersebut menjadi suatu hal yang baru yang berbeda dengan yang sudah ada, jadi ia tidak semata-mata menjiplak suatu hasil karya seni orang lain, akan tetapi ia merubah dengan menambahkan ciri khas yang ia miliki seperti menambahkan hidung merah atau manik-manik yang biasanya ia gunakan.

Hal ini juga sesuai dengan ciri-ciri kreativitas Menurut Slameto (2003:17) dalam Supriadi mengatakan bahwa ciri-ciri kreativitas dapat dikelompokkan dalam dua kategori yaitu:

- Kognitif

ciri kognitif diantaranya orisinilitas dalam berpikir, fleksibelitas, kelancaran, dan elaborasi (mengembangkan, memperkaya, memperinci) suatu gagasan. 
- Non kognitif

sedangkan ciri non kognitif diantaranya berkaitan dengan sikap atau perasaan yang meliputi rasa ingin tahu, bersifat imajinatif dan kepribadian kreatif.

Make up karakter yang dibuat oleh Cindercella termasuk dalam ciri non kognitif yang bersifat kreatif, ia mempunyai kreativitas dalam dirinya yang dapat ia tuangkan kedalam make up, dan juga cindercella bersifat imajinatif yang dimana ia dapat tuangkan kedalam make up yang ia buat yang berbeda dengan beauty vlogger lainnya yang berani komunikasikan kepada orang banyak. Dengan kreativitas yang dimiliki, ia tuangkan ke dalam make up dan berani menampilkan make up art dengan memberikan beberapa perintilan dan juga warna warni yang membuat make up nya terlihat unik dan kreative yang berbeda dengan make up pada umumnya. Menjadi kreative adalah kunci utama dalam melakukan make up art.

Menurut ahli kreatif yang dikemukakan dalam menanggapi make up art yang dilakukan oleh cindercella, bahwa menurut ia cindercella memiliki kreatifitas dalam membuat karyanya. Tentunya cindercella juga memiliki suatu konsep apa yang ingin ia tampilkan ke publik sehingga dapat membuat suatu karya tersebut. Selain itu juga menurut ia, make up yang dilakukan bukan hanya unsur colourfull yang membuat karya nya disebut kreatif tetapi ia bisa mewujudkan imajinasinya, dimana konsepnya menjadi suatu hasil karya make up dan disajikan ke publik yang menjadi bukti bahwa ia seorang yang kreative.

Pendapat yang sama juga dikemukakan oleh narasumber lainnya, yaitu juga seorang beauty influencer. Bahwa make up yang dilakukan oleh cindercella merupakan kreative dan juga unik, dari segi konsep yang ia lakukan dan menurutnya juga ia termasuk salah satu yang menjadi trensetter. Menurut ia sebelum ada cindercella make up aneh-aneh atau make up art ini di indonesia tidak sebanyak itu dan belum booming sehingga make up tersebut pun menjadi banyak orang ketahui dan juga make up karakter yang unik dan aneh yang dibuatnya itu menjadikan sebuah pengenalan kepada orang-orang yang menjadikan identitas diri bagi Cindercella yang banyak dikenali oleh orang banyak. Cindercella juga dapat dibilang sebagai sosok panutan bagi kalangan beauty influencer. Kreativitas juga dapat diartikan berbeda oleh setiap orang, dan menurut pandangan seseorang. Kembali lagi pada setiap individu yang melihatnya.

Dapat diketahui bahwa make up yang di buat oleh cindercella termasuk kreatif. Kreativitas pun dapat diartikan berbeda-beda oleh setiap orang, bagaimana tergantung oleh setiap individu yang melihatnya. Dengan begitu kreatifitas sangat dibutuhkan dalam suatu karya seni agar dapat menghasilkan suatu karya yang baik.

Dilihat dari hasil wawancara, peneliti mengidentifikasi bahwa make up karakter yang dibuat oleh cindercella dapat menjadikan sebuah identitas diri pada dirinya yang dikenal oleh banyak orang. Menjadi seorang beauty vlogger yang berbeda yang memiliki ciri khas juga dikenal dengan keunikan make up yang dibuat dan tingkah lakunya, dapat terlihat dari video yang diunggah di platform media sosial. Cindercella mempunyai kreatifitas dan keberanian untuk menunjukkan make up karakter yang ia buatnya berbeda, dan juga ia selalu ingin menjadi trensetter dengan melakukan suatu hal yang tidak terduga. 


\section{Simpulan}

Berdasarkan dari hasil penelitian ini mengenai cara mengkomunikasikan make up art yang dilakukan oleh cindercella, peneliti menarik kesimpulan beberapa hal, antara lain:

Make up juga merupakan suatu komunikasi sama halnya dengan Make up karakter. Make up yang dimana biasanya untuk mempercantik diri dan penampilan, namun Make up karakter yang dilakukan oleh cindercella memiliki tujuan yang berbeda dan dapat memberikan kesan cantik. Cindercella dapat mengkomunikasikan make up art tersebut sehingga membuat dirinya menjadi seseorang yang terlihat berbeda, kreatif dan unik yang dapat dikenal banyak orang sehingga menjadikan make up karakter tersebut sebagai identitas dirinya.

Tujuan Make up karakter yang telah dilakukan oleh Cindercella yaitu agar dirinya dapat menjadi seorang trensetter dengan melakukan Make up yang kreatif dan unik agar berbeda dari yang lainnya dengan menambahkan manik-manik yang ia lakukan untuk sehari-hari dan juga hidung merah. Untuk menjadikan sebagai sebuah ciri khas atau identitas yang melekat pada diri cindercella sendiri.

Menurut Beauty Influencer walaupun cindercella mempunyai keunikan sendiri dalam Make up karakternya dan kreatif, namun keunikannya itu belum bisa sepenuhnya dapat ia sampaikan dengan baik kepada viewers nya, karena menurutnya kurang konsisten dalam membuat konten video Make up karakter yang ia buat, yang menjadikan dirinya sebagai identitas yang dikenal oleh banyak orang. Namun terdapat perbedaan pendapat dengan ahli. Menurut ahli kreatif, Make up karakter yang dibuatnya sudah memberikan keunikan dan kreatifitas yang dapat dilihat oleh viewers dari Cindercella.

\section{Ucapan Terima Kasih}

Ucapan terima kasih penulis sampaikan kepada Cindercella dan narasumber lainnya yang telah bersedia meluangkan waktu untuk melakukan wawancara dan memberikan informasi kepada penulis. Penulis juga ingin berterimakasih kepada Dosen Pembimbing Gregorius Genep Sukendro dan seluruh pihak yang telah membantu penelitian ini serta pihak Fakultas Ilmu Komunikasi Universitas Tarumanagara.

\section{Daftar Pustaka}

Barker, Chris, 2004. Cultural Studies. Teori \& Praktik. Penerjemah: Nurhadi. Yogyakarta: Kreasi Wacana.

Effendy, Onong. Uchyana. (2006). Ilmu Komunikasi Teori dan Praktek. Bandung: PT. Remaja Rosdakarya.

Gunawan, Imam (2014). Metode Penelitian Kualitatif Teori dan Praktik. Jakarta: PT Bumi Aksara.

Moelong, Lexy J. (2012). Metedologi Penelitian Kualitatif. Bandung: PT. Remaja Rosdakarya.

Munandar, Utami. (2009). Pengembangan kreativitas Anak Berbakat. Jakarta : Rineka Cipta.

Nazir, Moh. (2011). Metode Penelitian. Bogor: Ghalia Indonesia. 
Vol. 3, No. 1, Juli 2019, Hal 196- 203

Rachmawati, Yeni \& Euis Kurniati. (2005). Strategi Pengembangan Kreativitas pada Anak Usia Taman Kanak-kanak. Jakarta : Depdikbud.

Slameto. (2003). Belajar dan Faktor-faktor Yang Mempengaruhinya. Jakarta: Rineka Cipta 